\title{
"LA TRANSICIÓN" VISTA DESDE LOS VALLES INTERMONTANOS DEL NOROESTE ARGENTINO: NUEVOS DATOS DE LA QUEBRADA DE LOS CORRALES (EL INFIERNILLO, TUCUMÁN, ARGENTINA) ${ }^{1}$
}

\author{
“THE TRANSITION" VIEWED FROM THE INTERMOUNTAINS BASINS OF THE \\ ARGENTINE NORTHWEST: NEW DATA OF QUEBRADA DE LOS CORRALES \\ (EL INFIERNILLO, TUCUMÁN, ARGENTINA)
}

\author{
Nurit Oliszewski², Jorge G. Martínez ${ }^{2}$, Guillermo A. Arreguez ${ }^{2}$, C. Matías Gramajo Bühler ${ }^{2}$ y \\ M. Eugenia Naharro
}

\begin{abstract}
La quebrada de Los Corrales (El Infiernillo, Tucumán, Argentina) se ubica por encima de los $3.000 \mathrm{msm}$ en el sector norte del Sistema de las Sierras del Aconquija. Los trabajos de investigación desarrollados hasta el momento permitieron identificar diversos tipos de evidencias arqueológicas correspondientes a distintos momentos de ocupaciones humanas que se inician en el Holoceno Medio inicial (ca. 7.800-600 a.p.). La larga secuencia ocupacional convierte a esta microrregión en un buen punto de partida para reflexionar acerca de diversos procesos prehispánicos ocurridos en el noroeste argentino desde las ocupaciones más tempranas hasta el establecimiento de una importante aldea agropastoril durante el $1^{\text {er }}$ milenio de la Era Cristiana. En este trabajo presentamos una serie de evidencias correspondientes al período de transición entre un modo de vida cazador-recolector a otro agropastoril ocurrido -a escala macrorregional- entre ca. 4.000 y 2.000 a.p. y evaluamos las posibilidades de la ocurrencia de un proceso transicional de carácter local.
\end{abstract}

Palabras claves: quebrada de Los Corrales, noroeste argentino, cazadores-recolectores, aldea agropastoril.

Quebrada de Los Corrales (El Infiernillo, Tucumán, Argentina) is located above 3,000 masl in northern sector of Sierras del Aconquija. The research carried out so far allowed the identification of diverse types of archaeological evidence corresponding to different moments of human occupation which began in the Middle Holocene (ca. 7,800-600 BP). This long occupational sequence of about 7,000 years makes Quebrada de Los Corrales a good starting point for reflecting on diverse pre-Hispanic processes that occurred in the Argentinean northwest from the early occupations to the establishment of an important agro-pastoral village during the first millennium of the Christian era. In this paper, we present a series of pieces of evidences corresponding to the period of transition from a hunter-gatherer way of life to an agro-pastoral one, which occurred-on a macro-regional scale-between ca. 4,000 and 2,000 years BP. We evaluated the possibilities of the occurrence of a local transitional process.

Key words: Quebrada de Los Corrales, northwest Argentina, hunter-gatherers, agro-pastoral village.

Desde hace más de una década investigamos en la quebrada de Los Corrales, El Infiernillo, Tucumán (Figuras 1 y 2) donde identificamos una aldea agropastoril denominada Puesto Viejo, ocupada durante los primeros siglos del $1^{\text {er }}$ milenio de la Era Cristiana (Oliszewski et al. 2015). Además, entre los objetivos de nuestro proyecto estuvo siempre tratar de resolver un viejo problema de la Arqueología del noroeste argentino (NOA) relacionado con la casi total ausencia de evidencias de grupos cazadores-recolectores en el área de los valles y quebradas, fuera del ámbito de la Puna. Con este objetivo se realizaron diversas prospecciones e intervenciones estratigráficas en la quebrada de Los Corrales (QDLC) las cuales proporcionaron, además de valiosa información sobre tempranas ocupaciones ocurridas hacia ca. 7.800 a.p., importantes evidencias de un intervalo del cual se tiene escasa información para esta área: el de la transición entre grupos cazadoresrecolectores y grupos agropastoriles ocurrida entre ca. 4.000 y 2.000 a.p.

\footnotetext{
1 Una primera versión de este artículo fue presentada en el XIX Congreso Nacional de Arqueología Argentina, Tucumán (agosto 2016), en el marco del simposio "El tránsito de modos de vida cazadores-recolectores a agro-pastoriles en la porción meridional de los Andes Centro-Sur: Trayectorias de continuidad y cambio". Este manuscrito fue evaluado por pares externos y editado por el Comité Editorial de Chungara y los editores invitados Marcela Sepúlveda, Salomón Hocsman y Francisco Gallardo.

2 Instituto Superior de Estudios Sociales (ISES)-CONICET / Universidad Nacional de Tucumán, Saavedra 254, 4000, Tucumán, Argentina. nuritoli@yahoo.com.ar; jormartin1969@yahoo.com.ar; puchiarreguez@hotmail.com; cmatiasb@gmail.com 3 Facultad de Ciencias Naturales e IML, Universidad Nacional de Tucumán, Miguel Lillo 205, 4000, Tucumán, Argentina. mariaeugenianaharro@yahoo.com.ar.
} 


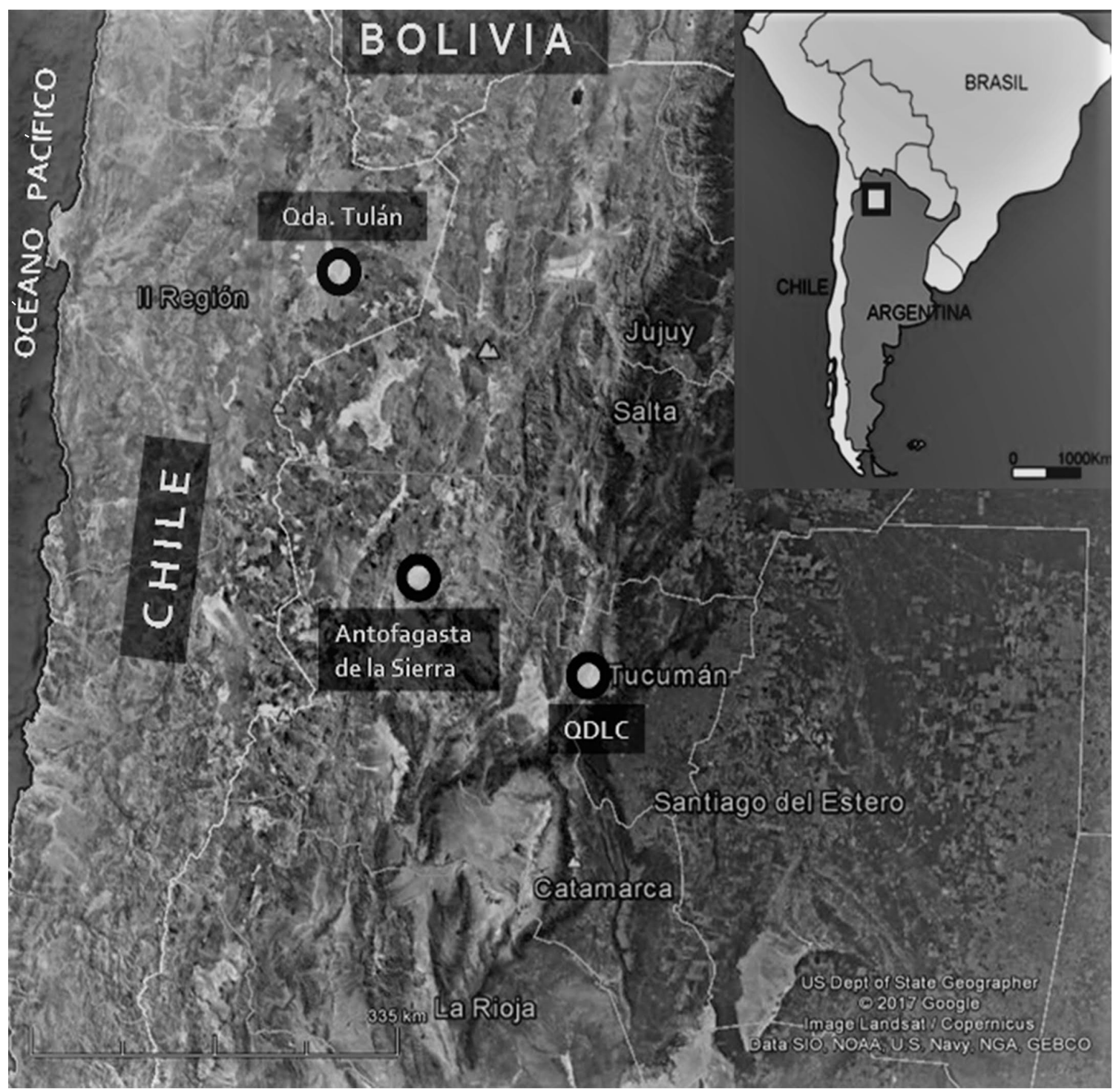

Figura 1. Ubicación geográfica relativa del área de estudio (QDLC). Relative geographical location of the study area $(Q D L C)$.

En el NOA, es en el ámbito de la Puna donde han sido registradas las evidencias de las primeras ocupaciones humanas ocurridas a fines del Pleistoceno (ca. 11.000 a.p.) y también del largo proceso que llevó a la producción de alimentos y a su consolidación como modo de vida dominante hasta la conquista española en el siglo XVI. Para Antofagasta de la Sierra, en la Puna sur argentina (Provincia de Catamarca) (Figura 1), Aschero y Hocsman (2011) propusieron la ocurrencia de un proceso transicional local entre 4.500 y 3.500 a.p. En el mismo, se habría dado una combinación de caza-recolección con una economía productiva de bajo nivel que implicaba una incipiente explotación de recursos vegetales y faunísticos domésticos. Como hipótesis propusieron para el lapso 3.500-2.000 a.p. una estrategia predominante de caza-recolección/pastoreo y hacia 2.000 a.p. el cambio hacia una estrategia de pastoreo/caza-recolección. En el norte de Chile se ha definido la trayectoria de un proceso sociocultural desde el Arcaico Tardío al Formativo Temprano en la quebrada de Tulán, que ha permitido definir su naturaleza transicional en un marco de complejidad social creciente que dio origen a sociedades formativas singulares en la subárea circumpuneña (Figura 1). A partir de la domesticación de camélidos lograda en Tulán 52, los grupos humanos de esta zona alcanzaron un consolidado sistema de integración social y regional con una amplia red de interacción de larga distancia, en donde Tulán 54 concluye erigiéndose como un centro regional de congregación social con un marcado 


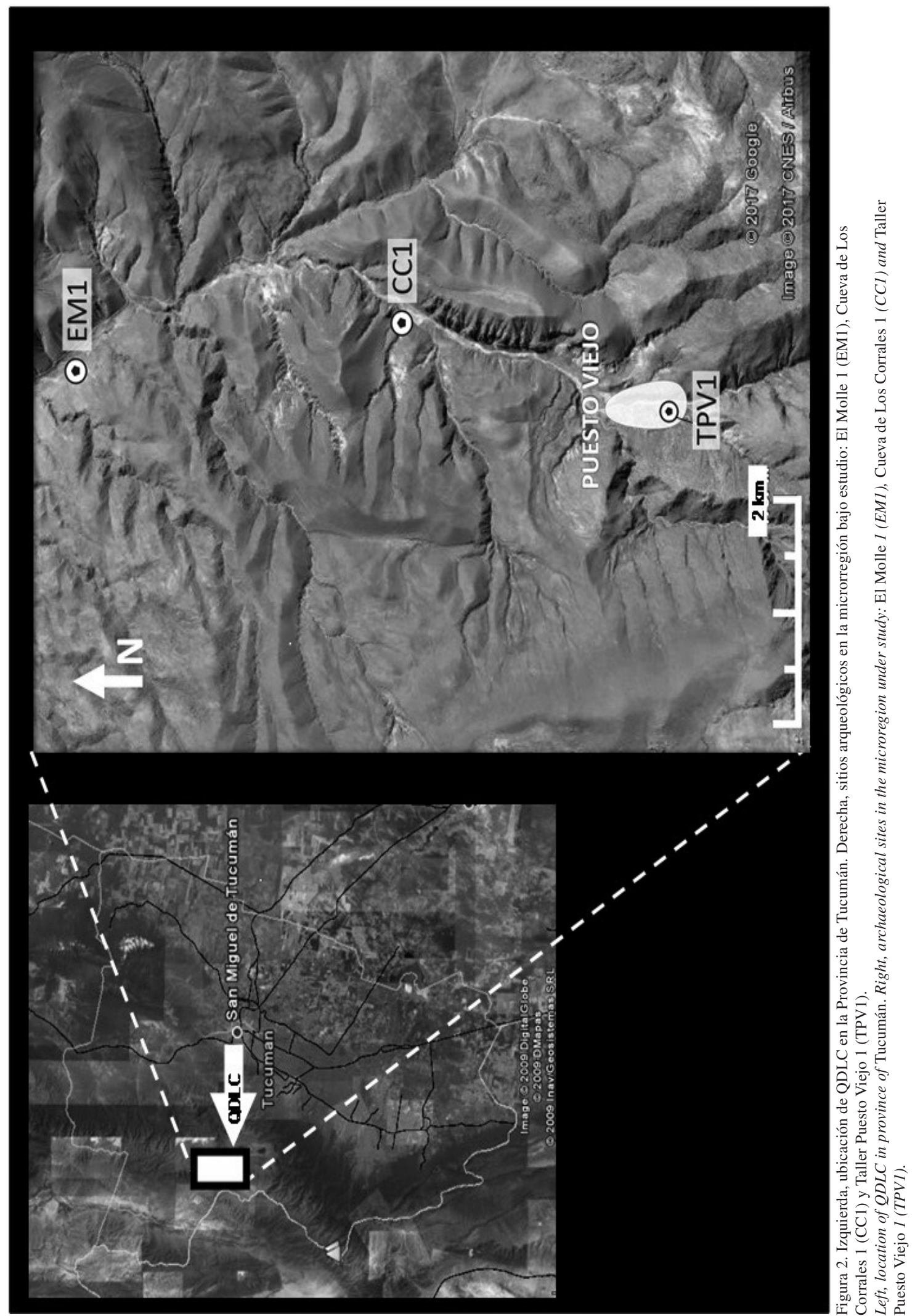


énfasis ceremonial (Núñez et al. 2006; 2017).

Ante la ausencia de registros de ocupaciones previas a las sociedades aldeanas productoras de alimentos, las investigaciones realizadas en el área de valles y quebradas intermontanos del NOA enfocaron tradicionalmente sus problemáticas casi por completo hacia el estudio de sociedades agropastoriles, generando abundante información sobre este tema, en desmedro de otros como el origen y/o la transición hacia ese modo de vida. Sin embargo, en los últimos años el panorama ha comenzado a cambiar ya que las investigaciones desarrolladas han revelado la existencia de un creciente número de sitios asignables al Holoceno Medio y a momentos transicionales datados hacia 3.500 a.p. Tal es el caso de Soria 2 en el valle de Santa María
(Palamarczuk et al. 2007), Cardonal y Bordo Marcial en el valle del Cajón (Scattolin et al. 2015) y en la quebrada de Amaicha, El Divisadero (Gómez Augier y Caria 2012) y Planchada La Puntilla (Baied y Somonte 2013). Si bien aún no se puede plantear en ninguno de estos casos la presencia de procesos transicionales locales, como ocurre para la Puna argentina y chilena, resulta alentador en cuanto al aporte que implica poder avanzar en la comprensión integral del paso de un modelo extractivo basado en la caza/recolección asociado a una alta movilidad residencial hacia una economía de producción pastoril/agrícola vinculada a un sedentarismo pleno.

En el presente trabajo damos a conocer nuevas evidencias de QDLC para el lapso 4.000-2.000 a.p. con

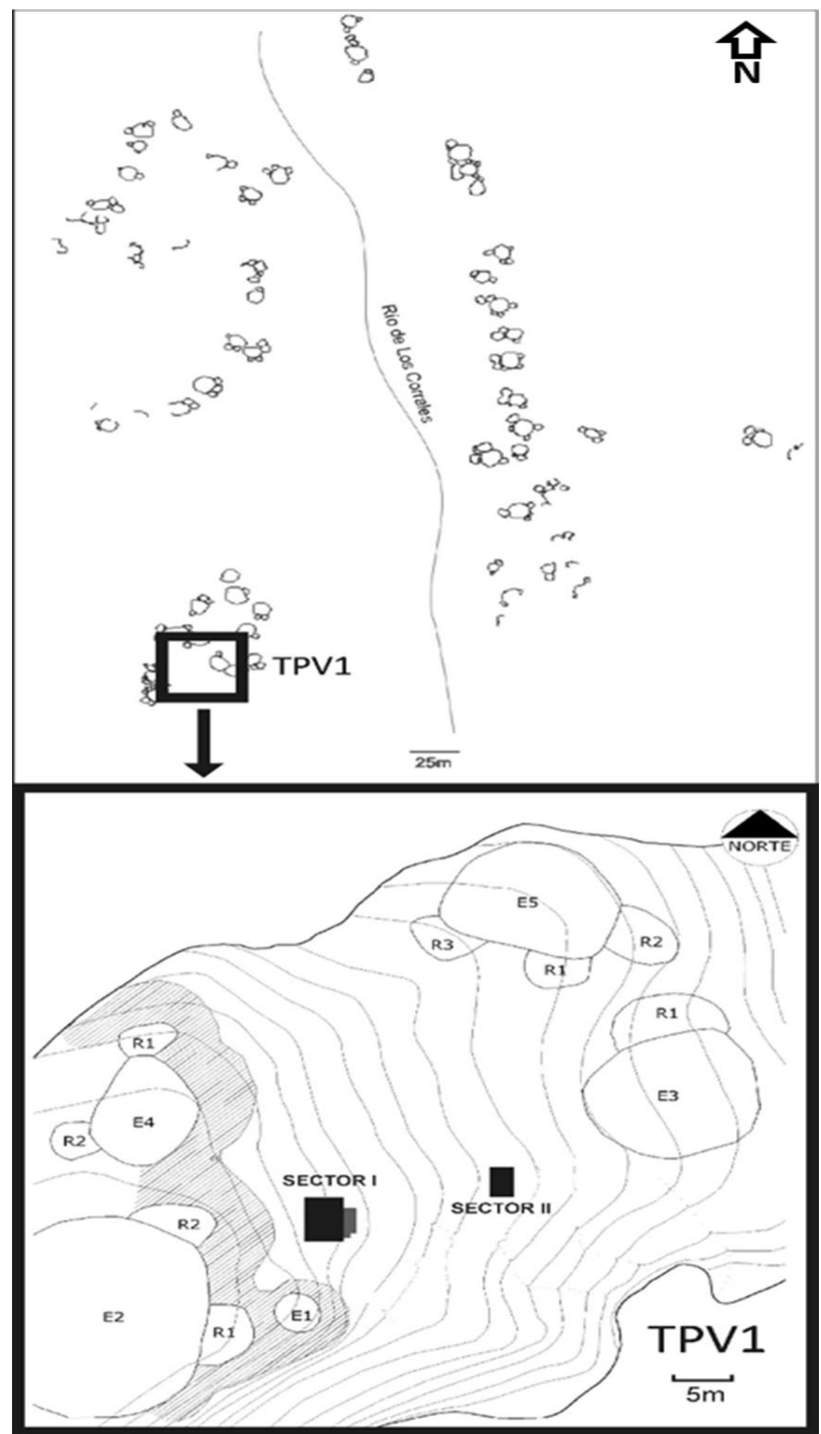

Figura 3. Arriba, mapa de la aldea Puesto Viejo y ubicación de TPV1, modificado de Di Lullo (2012). Abajo, ubicación de los Sectores I y II en el sitio TPV1, modificado de Martínez et al. (2013).

Above, map of Puesto Viejo village and location of TPV1, modified from Di Lullo (2012). Below, location of Sectors I and II in the TPVI site, modified from Martínez et al. (2013). 
el objeto de evaluar la probable ocurrencia de un proceso transicional local. Somos conscientes de la complejidad implícita en lo que probablemente sea el cambio más importante ocurrido en el extenso desarrollo cultural prehispánico del NOA y del área andina en general. Por lo tanto, este trabajo es un primer aporte en esta dirección, enfocando la problemática desde múltiples líneas de análisis.

\section{Las Evidencias de Momentos Previos a la Instalación Aldeana Agropastoril en QDLC}

QDLC está ubicada por sobre de los 3.000 msm en la zona del abra de El Infiernillo, límite norte del sistema montañoso del Aconquija (Figuras 1, 2 y 3). La historia ocupacional prehispánica de esta quebrada fue bastante extensa abarcando desde ca. 7.800 hasta 600 a.p. (Martínez et al. 2013; 2016; Oliszewski et al. 2015). La ocupación más intensa tuvo lugar durante los primeros siglos de la Era Cristiana (1.850-1.550 a.p.) materializada en un conjunto aldeano de al menos 85 unidades residenciales de diseño patrón Tafí concentradas en el curso superior del río de Los Corrales en la localidad arqueológica Puesto Viejo (Figura 3) y asociadas a extensas áreas productivas conformadas por aproximadamente 500 hectáreas de andenes de cultivo y 250 corrales (Di Lullo 2012;

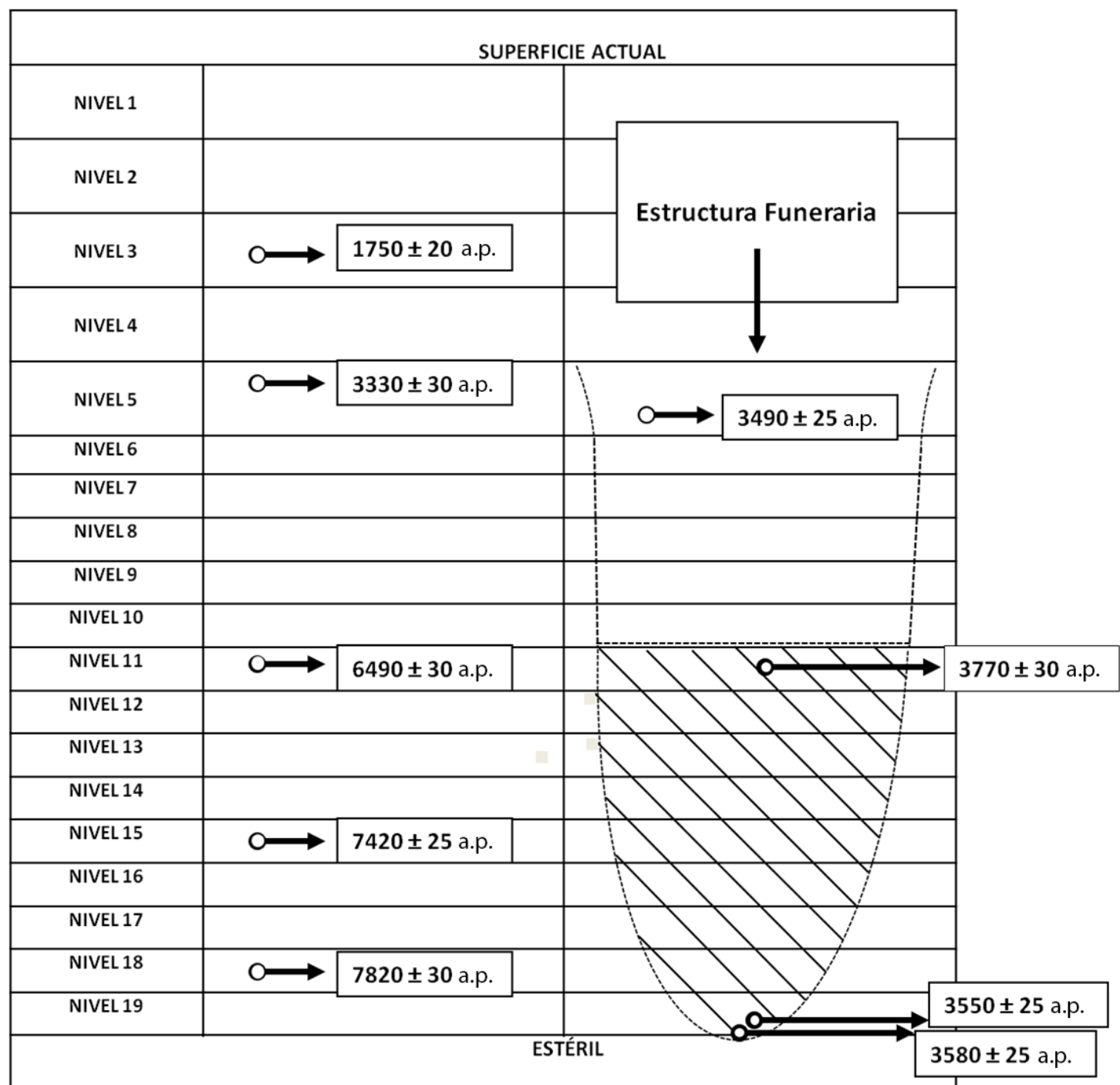

Figura 4. Esquema crono-estratigráfico de TPV1 (Sector I). A la izquierda, niveles estratigráficos con dataciones radiocarbónicas. A la derecha, situación de la estructura funeraria de la Cuadrícula C1. El área rayada corresponde a los niveles de sedimento carbonoso con la mayor densidad de restos humanos termoalterados.

Chronostratigraphic scheme of TPVI (Sector I). On the left, stratigraphic levels with radiocarbon dating. To the right, situation of the funerary structure of Grid C1. The striped area corresponds to the levels of carbonaceous sediment with the highest density of thermally altered human remains. 
Tabla 1. Dataciones radiocarbónicas de QDLC correspondientes al lapso 4.000-2.000 años a.p.

Radiocarbon dating of QDLC corresponding to the period 4,000-2,000 years $B P$.

\begin{tabular}{|c|c|c|c|c|c|}
\hline Procedencia & $\begin{array}{c}\mathrm{N}^{\circ} \mathrm{de} \\
\text { laboratorio }\end{array}$ & $\begin{array}{l}\text { Material } \\
\text { fechado }\end{array}$ & $\begin{array}{l}\text { Años } \\
\text { a.p. }\end{array}$ & \pm & $\begin{array}{c}\delta^{13} \mathrm{C} \\
\% 0\end{array}$ \\
\hline $\begin{array}{l}\mathrm{CC} 1 \text { Capa } 2^{\circ} \\
\left(3^{\circ} \text { extracción }\right)\end{array}$ & $\begin{array}{l}\text { UGAMS\# } \\
01616\end{array}$ & Paja & 2.100 & 200 & $-22,7$ \\
\hline El Molle 1 & $\begin{array}{l}\text { UGAMS\# } \\
22271\end{array}$ & $\begin{array}{l}\text { Hueso } \\
\text { humano }\end{array}$ & 2.210 & 20 & $-22,8$ \\
\hline $\begin{array}{l}\text { CC1 Capa } 2^{\circ} \\
\left(3^{\circ} \text { extracción }\right)\end{array}$ & $\begin{array}{l}\text { UGAMS\# } \\
22268\end{array}$ & Semilla & 3.040 & 30 & $-28,3$ \\
\hline $\begin{array}{l}\text { TPV1 Sector II } \\
\text { Nivel } 2 \\
\text { ( } 4^{\circ} \text { extracción) }\end{array}$ & $\begin{array}{l}\text { UGAMS\# } \\
22273\end{array}$ & $\begin{array}{l}\text { Hueso } \\
\text { humano }\end{array}$ & 3.300 & 25 & $-19,6$ \\
\hline $\begin{array}{l}\text { TPV1 Sector I } \\
\text { Nivel } 5 \text { cumbre }\end{array}$ & $\begin{array}{l}\text { UGAMS\# } \\
07515\end{array}$ & $\begin{array}{l}\text { Hueso } \\
\text { animal }\end{array}$ & 3.330 & 30 & $-21,4$ \\
\hline $\begin{array}{l}\text { TPV1 Sector I } \\
\text { Nivel } 5 \text { piso }\end{array}$ & $\begin{array}{l}\text { UGAMS\# } \\
25519\end{array}$ & $\begin{array}{l}\text { Hueso } \\
\text { humano }\end{array}$ & 3.490 & 25 & $-19,3$ \\
\hline $\begin{array}{l}\text { TPV1 Sector I } \\
\text { (estructura } \\
\text { funeraria) }\end{array}$ & $\begin{array}{l}\text { UGAMS\# } \\
22894\end{array}$ & Carbón & 3.550 & 25 & $-21,2$ \\
\hline $\begin{array}{l}\text { TPV1 Sector I } \\
\text { (estructura } \\
\text { funeraria) }\end{array}$ & $\begin{array}{l}\text { UGAMS\# } \\
22893\end{array}$ & $\begin{array}{l}\text { Diente } \\
\text { humano }\end{array}$ & 3.580 & 25 & $-18,8$ \\
\hline $\begin{array}{l}\text { TPV1 Sector I } \\
\text { (estructura } \\
\text { funeraria) }\end{array}$ & $\begin{array}{l}\text { UGAMS\# } \\
25521\end{array}$ & $\begin{array}{l}\text { Diente } \\
\text { humano }\end{array}$ & 3.770 & 30 & $-18,7$ \\
\hline
\end{tabular}

Oliszewski et al. 2015). Las evidencias de ocupaciones previas a momentos aldeanos provienen de tres loci (Figura 2): Taller Puesto Viejo 1 (TPV1), Cueva de los Corrales 1 (CC1) y El Molle 1 (EM1) (Figuras 1 y 2). No obstante, aclaramos que el mayor volumen de información procede, como se apreciará a continuación, del sitio TPV1.

\section{Taller Puesto Viejo 1}

Este sitio se ubica en la pendiente oeste del valle del río Los Corrales y consiste en una concentración de evidencias prehispánicas en un espacio a cielo abierto (34 x $24 \mathrm{~m}$ ), el cual se encuentra delimitado por unidades residenciales patrón Tafí del $1^{\text {er }}$ milenio de la Era Cristiana (Figuras 2 y 3). Su principal característica es la singularidad de presentar materiales arqueológicos en estratigrafía asignables al Holoceno Medio, lo cual es muy poco frecuente en el área de valles y quebradas para dichas cronologías.

Diversas campañas fueron realizadas en este sitio, habiéndose intervenido en dos áreas separadas una de otra por $10 \mathrm{~m}$ (Figura 3): Sector I (superficie excavada = $18 \mathrm{~m}^{2}$ ) y Sector II (superficie excavada $=8 \mathrm{~m}^{2}$ ). Ambos sectores cuentan con una alta densidad de materiales arqueológicos en estratigrafía, destacándose la excelente preservación de restos óseos animales y humanos. Sin embargo, y a pesar de su cercanía, no hemos podido establecer una vinculación funcional entre uno y otro: el Sector I ha sido definido como una base residencial (Martínez et al. 2013) cuya crono-estratigrafía sintetiza la historia ocupacional prehispánica de QDLC desde ca. 7.800 años a.p. hasta el $1^{\text {er }}$ milenio de la Era Cristiana (Figura 4; Tabla1), en cambio el sector II aún no tiene adjudicada una funcionalidad específica.

En el Sector II fue detectada una asociación de restos humanos conformada por un cráneo fragmentado, dientes, un omóplato, un húmero, fragmentos de costillas y escasas astillas óseas que habrían pertenecido a un mismo individuo. Una datación realizada sobre un fragmento del cráneo arrojó un resultado de $3.300 \pm 25$ a.p., contemporánea al Nivel 5 del Sector I (Figura 4; Tabla 1). Los restos se encontraban desarticulados y dispersos en una matriz sedimentaria homogénea (limo-arenosa), sin una estructura funeraria propiamente, contrario a lo que ocurre posteriormente en esta misma quebrada para momentos agropastoriles, donde los entierros se practicaban en cistas de piedra en el interior de las viviendas (Oliszewski et al. 2010). La disposición espacial azarosa de las partes esqueletarias de este individuo no permite precisar aún que haya sido enterrado ex profeso ya sea de forma primaria o secundaria.

En el Sector I, en una campaña reciente realizada en 2015, fueron detectados dos pozones contiguos o estructuras de cavado sin ningún tipo de revestimiento o delimitación. En su interior se encontraban numerosos restos humanos altamente fragmentados y termoalterados casi en su totalidad, habiéndose podido identificar durante la excavación diversos fragmentos de cráneo, epífisis, falanges y piezas dentarias. Los mismos fueron datados entre ca. 3.770 y 3.490 a.p. y estaban completamente incorporados a una matriz areno-carbonosa de combustión. El núcleo de combustión propiamente dicho, que estaba conformado por sedimento carbonoso y numerosos fragmentos de carbones vegetales, fue registrado en los niveles inferiores (Niveles 18 y 19). El análisis de varios indicadores sobre los conjuntos de restos humanos permite afirmar que se trata del resultado de prácticas crematorias in situ (Martínez et al. 2017). Dentro de este contexto funerario fueron recuperados distintos tipos de evidencias. Una de ellas refiere a un aspecto muy relevante de TPV1 relacionado con el hallazgo de semillas termoalteradas de quínoa (Chenopodium quinoa Willd. cfr.), las cuales fueron recuperadas del interior de los mencionados pozones. Los macrorrestos vegetales se sitúan cronológicamente dentro del lapso 3.770-3.490 a.p., al igual que los restos humanos asociados estratigráficamente. Estas semillas fueron detectadas en tres niveles $(13,15$ y 16$)$ a partir del análisis macroscópico de muestras de sedimentos tomadas del interior de los pozones y cuadrículas 


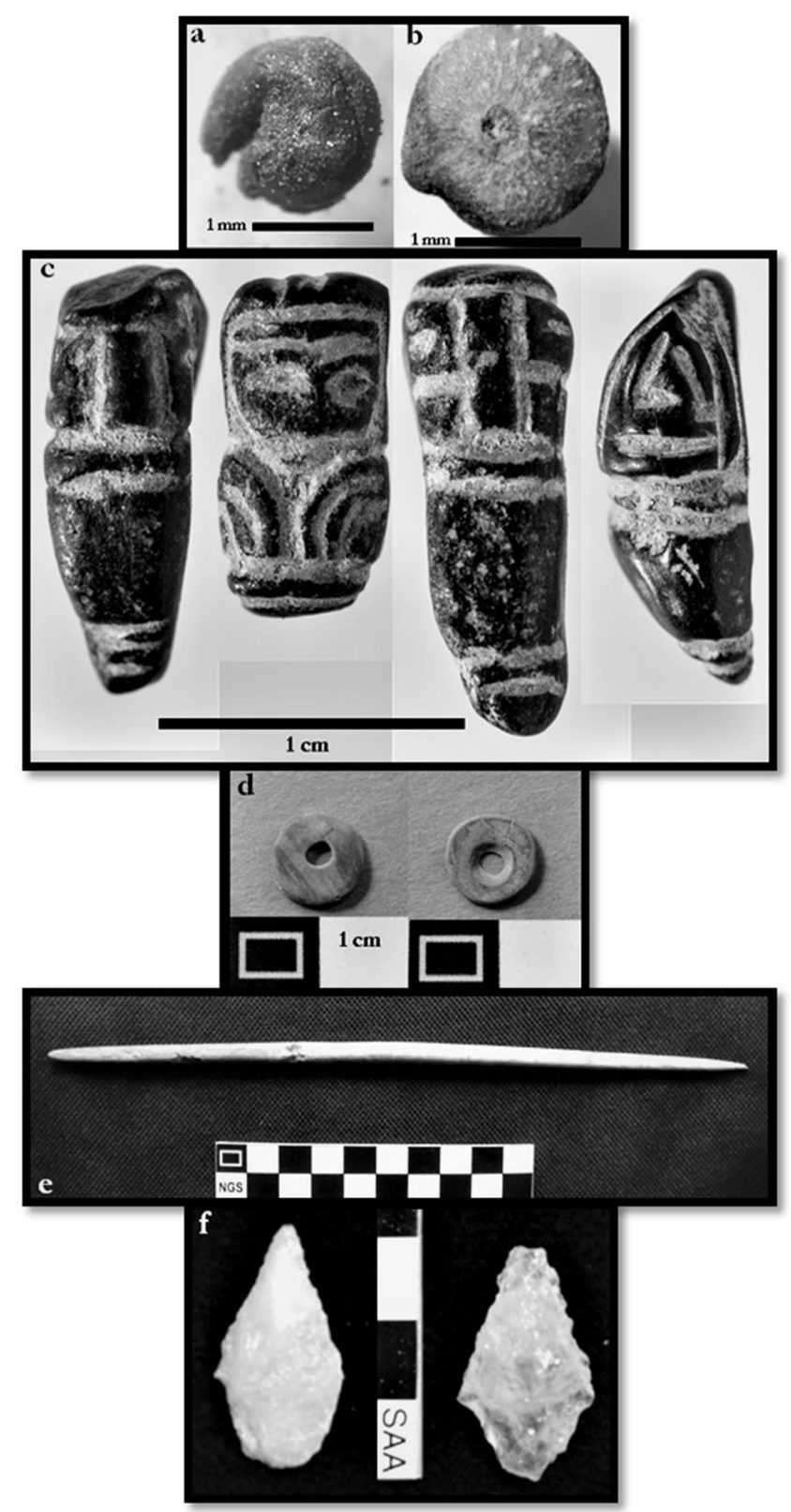

Figura 5. Evidencias de QDLC (todas procedentes de TPV1-Sector I con excepción de la semilla seca que procede de CC1): (a) semilla de Chenopodium quinoa cfr. termoalterada, (b) semilla de Ch. quinoa seca, (c) cuentas líticas, (d) cuenta de molusco marino, (e) "aguja"de hueso, (f) puntas de proyectil de cuarzo.

Evidences of QDLC (all from TPV1-Sector I except dry seed coming from CC1): (a) thermally altered Chenopodium quinoa $c f r$ seed, (b) dried $\mathrm{Ch}$. quinoa seed, $(c)$ lithic beads, $(d)$ sea mollusc bead, $(e)$ bone "needle", $(f)$ quartz projectile points.

adyacentes. La muestra total recuperada se compone de cinco especímenes termoalterados aunque muy bien conservados desde el punto de vista morfológico, lo cual permitió su identificación taxonómica a nivel de especie (Figura 5a). También fue registrada en el nivel 13 una semilla de algarrobo (Prosopis sp.). Además de estas semillas alimenticias y exclusivamente del interior de las estructuras de inhumación se recuperaron 246 semillas termoalteradas de entre $1 \times 1$ y $2 \times 2 \mathrm{~mm}$. A pesar de no haberse preservado caracteres diagnósticos que permitan identificar géneros y/o especies, estas pequeñas semillas pueden ser atribuidas a plantas silvestres no alimenticias como cactáceas y poáceas locales que probablemente fueron empleadas como combustible en los mencionados procedimientos de cremación.

Además, en asociación a las estructuras de cavado, destacamos el hallazgo de cuentas de collar confeccionadas en diferentes materiales como rocas 


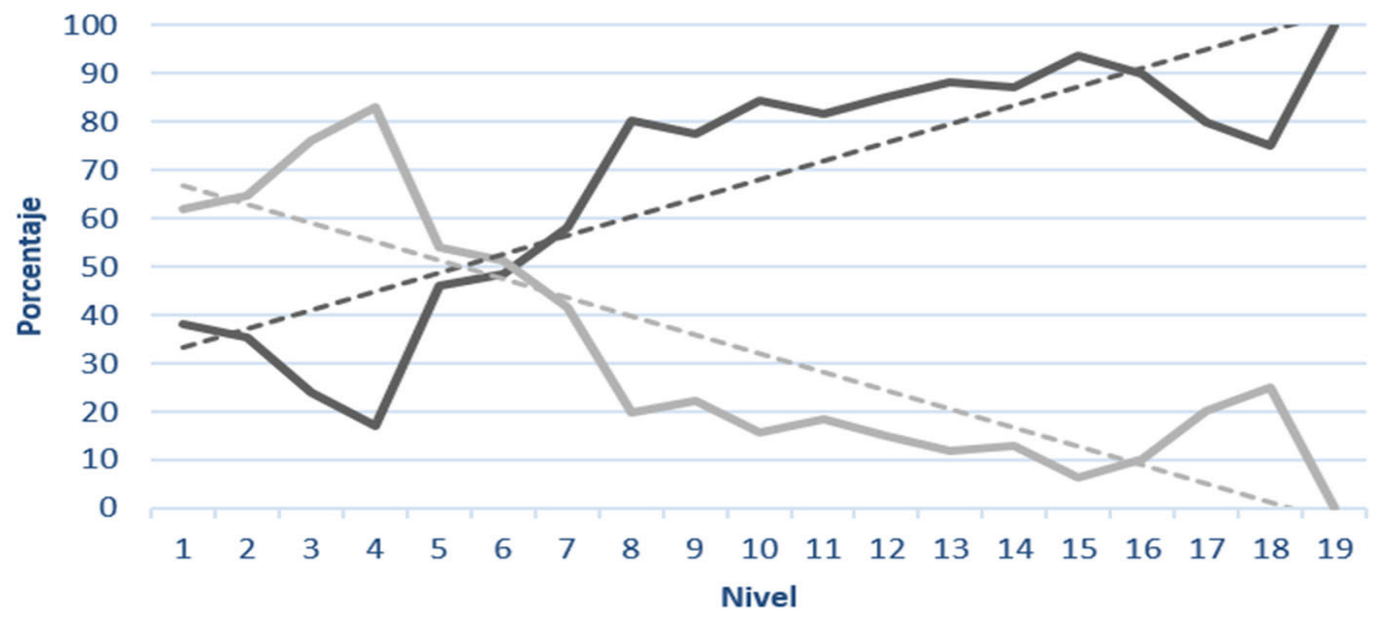

Andesita Cuarzo - - - Lineal (Andesita) - - - - Lineal (Cuarzo)

Figura 6. Uso de materias primas líticas en la secuencia estratigráfica de TPV1.

Use of lithic raw materials in the stratigraphic sequence of TPV1.

volcánicas, valvas de moluscos marinos y barro endurecido. Se trata de cuatro cuentas líticas decoradas con motivos geométricos y antropomorfos (Figura 5c), una cuenta circular de valva marina procedente del océano Pacífico situado a $480 \mathrm{~km}$ de distancia lineal (Figura 5d) y cuatro cuentas de barro endurecido que serían parte de pequeñas celdillas de un himenóptero (Jorge Genise comunicación personal 2016). Otro elemento recuperado en una de las estructuras es una fina "aguja" de hueso aún sin funcionalidad definida (Figura 5e).

Describiremos a continuación otros tipos de evidencias detectados dentro del mismo Sector I de TPV1, los cuales tienen una historia crono-estratigráfica diferente a la de los pozones funerarios (Figura 4).

Para el lapso 4.000-2.000 a.p. (Niveles 4, 5 y 6) fueron registrados diversos artefactos líticos de molienda confeccionados por picado/pulido. En total se recuperaron ocho piezas (enteras y fracturadas) las cuales fueron manufacturadas con rocas locales (granitos y metamórficas). Sólo una de ellas corresponde a un molino plano (pasivo) y el resto son manos simples y dobles de formato discoidal $(\mathrm{ca} .10 \mathrm{x} 15 \mathrm{~cm})$ con rebajes en cara y canto. Debemos destacar que también en niveles inferiores $(8,9$ y 10$)$ asociados al bloque temporal definido entre ca. 6.500-3.500 a.p. fueron detectados tres molinos planos y dos manos. Análisis de microfósiles en curso permitirán especificar el tipo de sustancias que fueron procesadas (ya sea orgánicas o inorgánicas) y conocer el espectro probable de consumo/ manejo de plantas silvestres y/o domésticas. Asociado a estos niveles se recuperó un endocarpo termoalterado de chañar (Geoffroea decorticans Jack).

Respecto a la tecnología lítica de talla y considerando el rango temporal de interés de este trabajo, el análisis de desechos de talla procedentes del Sector I denota un abundante uso de materias primas locales (superior al 93\% en todos los niveles de la secuencia) dado por andesita y cuarzo (Martínez et al. 2013). No obstante fue identificada una covariación inversa de uso a lo largo de toda la secuencia entre estas dos rocas. Desde los niveles inferiores (Niveles 18-19, ca. 7.800 a.p.), la frecuencia de la andesita sobrepasa notablemente a la del cuarzo. Considerando estas dos materias primas, la dominancia de andesita comienza a disminuir gradualmente desde el Nivel 10 (ca. 6.500 a.p.) y en el Nivel 6 (ca. 3.500 a.p.) esta proporción cambia abruptamente volviéndose más frecuente el uso de cuarzo, manteniéndose esta tendencia hacia momentos posteriores (Figura 6).

Destacamos entre las rocas minoritarias la presencia de desechos de talla de obsidiana en toda la secuencia desde las ocupaciones más antiguas de TPV1 hasta el $1^{\text {er }}$ milenio de la Era Cristiana. Si bien la cantidad de muestras es reducida $(\mathrm{N}=9)$ denota una alta relevancia arqueológica por la movilidad que implica este recurso no local, dado que todos provienen de fuentes ubicadas al oeste en la Puna meridional argentina (Dpto. Antofagasta de la Sierra) a una distancia mínima de 140 km lineales (Figura 1) (Martínez et al. 2016).

En cuanto a los artefactos formatizados, dentro de los niveles bajo análisis $(4,5$ y 6$)$, se registró un total de 23 piezas donde el cuarzo es la materia prima mayoritaria $(47,8 \%)$ seguida de la andesita $(34,7 \%)$. Las puntas de proyectil constituyen el grupo tipológico dominante $(\mathrm{N}=5)$, registrándose diseños con pedúnculo esbozado y limbo triangular de tamaño mediano-pequeño, en el que el cuarzo también tiene mayor frecuencia $(60 \%$ de los casos incluyendo preformas). Este tipo de punta 
de proyectil de cuarzo sólo se registra a partir del nivel 6 (y en niveles superiores) en la secuencia de TPV1, el cual es el diseño-tipo casi estándar de las ocupaciones aldeanas posteriores (Figura 5f). Las mismas se asocian por sus características dimensionales al sistema de arma arco/flecha.

Los restos arqueofaunísticos en QDLC asignables al lapso de interés son muy numerosos, habiéndose procesado hasta el momento los materiales procedentes de tres cuadrículas del Sector I $\left(3 \mathrm{~m}^{2} / 18 \mathrm{~m}^{2}\right)$. De un total de 1673 elementos óseos para toda la secuencia (ca. 7.800-1.750 a.p.) el NISP se definió en 1328 (79\%). La integridad del conjunto es buena (baja meteorización, poca alteración por carnívoros y nula por roedores). Para los niveles transicionales ( 4,5 y $6 ; 11,5 \%$ del NISP) se identificaron los siguientes taxones: Aves, Dasypodidae, Ctenomydae y Camelidae (Izeta et al. 2016). Este último es el único taxón presente en toda la secuencia desde los niveles tempranos del Holoceno Medio (ca. 7.800 a.p.) hasta el $1^{\text {er }}$ milenio de la Era Cristiana (ca. 1.750 a.p.). Para los momentos más tempranos los morfotipos son más grandes que el del guanaco andino, pero debido al estado fragmentario de los huesos no pudo distinguirse por el momento ningún cambio hacia el lapso de interés, pensando en la probabilidad de identificar camélidos domésticos (Izeta et al. 2016). No obstante sí puede destacarse que la frecuencia de restos de Camelidae se incrementa notablemente hacia los niveles transicionales (alcanza el 25\% del total) en relación a los niveles previos donde nunca supera el 9,7\% (del NISP de cada nivel).

En cuanto a la tecnología cerámica, los análisis realizados en la secuencia del Sector I revelaron la presencia de 46 fragmentos cerámicos: 25 provenientes de los niveles 1 al 3 (asociados al $1^{\text {er }}$ milenio de la Era Cristiana) y 21 provenientes de los niveles 4 al 6 (asociados a cronologías transicionales motivo de este trabajo). Cabe destacar la integridad de estos materiales ya que el tipo de alteración de superficie, el bajo grado de meteorización, el escaso grado de esfericidad y redondez y la posición horizontal, denotan que los mismos no sufrieron procesos migratorios (Mercuri et al. 2016). Si bien hay algunas diferencias en cuanto al acabado de superficie ya que sólo para el $1^{\text {er }}$ milenio de la Era Cristiana se registran fragmentos pintados, pulidos y engobados asignables a estilos decorativos como Vaquerías, Condorhuasi y Tafí, se pudieron observar similitudes en lo que respecta al tipo de pasta, la densidad de inclusiones y el tipo de cocción para ambos momentos. En cuanto a las formas presentes, se observa una clara tendencia temporal hacia una mayor diversidad: las cerámicas oxidantes de pasta gruesa y alisada asociadas a formas globulares/subglobulares grandes usualmente interpretadas tanto como contenedoras de líquidos o sólidos como para cocinar se encuentran en toda la secuencia pero disminuyen su frecuencia hacia el $1^{\text {er }}$ milenio de la Era Cristiana (de 65,2 \% a 43,0 \%) y se registran cerámicas de cocción reductora y pasta fina asociadas a formas abiertas, pequeñas, de base cóncava convexa, por lo general pucos o cuencos utilizados posiblemente para servir y/o consumir líquidos. La mayor cantidad de fragmentos cerámicos con marcas de termoalteración (tizne) corresponde al primer grupo de cerámicas. Para establecer las formas se tuvieron en cuenta los antecedentes para áreas próximas (Bugliani et al. 2008; Gramajo Bühler 2009; Spano y Álvarez Larrain 2015; entre otros).

\section{Cueva de Los Corrales 1}

Cueva de Los Corrales 1 (CCl) es un sitio bajo reparo situado a $3 \mathrm{~km}$ al norte de TPV1 y cuenta también con una secuencia ocupacional persistente (3.050-650 a.p.). Se trata de una pequeña cueva en la cual se distinguió un sector de cueva propiamente dicho (interior) y otro de alero (exterior), teniendo en conjunto un ancho y profundidad de 4,70 por 7,60 m (Oliszewski et al. 2008). Está situada en la margen oeste del río de Los Corrales, habiéndose detectado por una parte, una secuencia estratigráfica de $30 \mathrm{~cm}$ de potencia y por otra, catorce morteros confeccionados en la roca de base. En casi todos los casos, dichos morteros presentan un relleno intencional compuesto por restos animales, vegetales y minerales, los cuales fueron puestos a presión y luego sellados por el agregado de un sedimento arcilloso muy compactado y termoalterado. Gramajo Bühler (2011) propuso que la acción de sellado de los morteros habría tenido connotaciones prácticas cuyo objetivo era aprovechar una porción mayor del poco espacio disponible de la cueva que no supera los 30 $\mathrm{m}^{2}$ (el relleno de los morteros pudo haber sido colocado intencionalmente a presión para dar sustento al sello y evitar que se desplome). Las excelentes condiciones naturales de preservación permitieron la recuperación de una gran diversidad de restos arqueológicos tanto de origen inorgánico como orgánico. Dicho contexto permitió definir que se trataba de un sitio de actividades múltiples, aunque estrictamente no fue un espacio doméstico de uso permanente. En cuanto a su ubicación temporal $\mathrm{CC} 1$ presenta dos momentos claros de uso con un importante hiatus entre ambos: las primeras ocupaciones ocurrieron hacia ca. 2.100 a.p. en momentos agropastoriles tempranos y la ocupación final en momentos tardíos hacia ca. 650 a.p. (Oliszewski et al. 2008).

Para la ocupación de ca. 2.100 a.p. (Capa $2^{\circ}$, $3^{\circ}$ extracción) pudieron establecerse funciones de procesamiento, consumo y descarte de recursos alimenticios animales como camélidos (Srur 2009) y vegetales como algarrobo, chañar, quínoa, maíz y zapallo (Oliszewski y Arreguez 2015). Recientemente fue datada una de las semillas de quínoa (Chenopodium quinoa Willd.) de esta misma capa, la cual proporcionó una datación de ca. 3.040 a.p. ampliando por lo tanto el rango temporal de ocupación de esta cueva (Figura 5b, Tabla 1). 


\section{EI Molle 1}

Finalmente, El Molle 1 (EM1) se ubica a 6 $\mathrm{km}$ hacia el norte de TPV1 y se caracteriza por la presencia de unidades domésticas patrón Tafí típicas del $1^{\text {er }}$ milenio de la Era Cristiana y semejantes a las que componen el núcleo aldeano de Puesto Viejo. En esta zona se realizó una intervención de rescate de un individuo que se encontraba articulado preservándose gran parte de sus huesos pero fragmentados la mayoría (cráneo, dientes, omóplatos, vértebras, costillas, coxales y huesos de miembros superiores e inferiores). El individuo estaba contenido por una estructura funeraria conformada por tres rocas alargadas de porte mediano/grande que lo rodeaban y una de forma tabular que actuaba como tapa del entierro (Di Lullo et al. 2014). Esta estructura se encuentra en la actual barranca del río y no tiene vinculación alguna con las unidades domésticas que se ubican muy próximas sobre la terraza fluvial. Se realizó una datación radiocarbónica que proporcionó un fechado de $2.210 \pm 20$ a.p., es decir previo a la instalación aldeana de Puesto Viejo (Tabla 1).

\section{Discusión}

Discutiremos a continuación el significado y relevancia de algunos de los ítems materiales y prácticas presentados en el apartado anterior, con el fin de evaluar continuidades y cambios en el lapso de interés en el cual nos centramos (ca. 4.000-2.000 a.p.) en relación a momentos previos y posteriores. Finalmente nos interesa destacar cómo se vinculan entre sí las distintas líneas, intentando caracterizar este lapso de transición entre grupos cazadoresrecolectores y sociedades agropastoriles en QDLC.

Por el momento, no contamos con ningún tipo de evidencia funeraria previa a las detectadas para el rango 3.800-3.300 a.p. Dentro de este lapso, fueron registrados en dos sectores separados dentro del área de TPV1 dos contextos funerarios diferenciados en cuanto a sus prácticas. Como se detalló antes, hacia ca. 3.300 a.p. en el Sector II se observa el caso de una asociación de restos humanos dispuestos en forma no anatómica y sin elementos de acompañamiento. Análisis tafonómicos en curso brindarán resultados que nos ayuden a definir mejor este caso.

Mucho más complejo es el contexto de las estructuras de cavado detectadas en el Sector I, las cuales fueron datadas entre ca. 3.770-3.490 a.p. Este caso es completamente distinto al del Sector II, por todo lo que implica en términos simbólicos la realización de prácticas crematorias, pudiéndose tratar probablemente de más de un evento de cremación, con depositaciones y/o remociones sucesivas dentro del lapso mencionado. Este tipo de tratamiento mortuorio representa, por el momento, el caso más antiguo de cremación en el ámbito del NOA, práctica que no tuvo continuidad en momentos posteriores.

El otro enterratorio que completa el registro funerario para el lapso de interés, corresponde al individuo del sitio El Molle 1 datado en ca. 2.210 a.p. Tratándose de un entierro directo dentro de una especie de cista de piedra, amplía aún más la variabilidad existente dentro de las prácticas mortuorias para este período transicional pre-aldeano en nuestra área de estudio. Ya en el período aldeano (a partir de ca. 2.000 a.p.) registramos en Puesto Viejo $1(480 \mathrm{~m}$ al norte de TPV1) el hallazgo de un entierro directo en cista en el interior de una vivienda, datado en ca. 1.560 a.p. (Oliszewski et al. 2010) el cual tiene elementos de semejanza que podrían conectarlo con el del sitio EM1, con la diferencia de que este último se encuentra aislado ya que es previo a la instalación aldeana del $1^{\text {er }}$ milenio de la Era Cristiana. Cabe destacar que a pesar de las notorias diferencias entre ambos tipos de prácticas inhumatorias, los posibles eventos de cremación ocurridos 2.000 años antes presentan una similitud con los entierros en cistas en las viviendas aldeanas y refiere a que las áreas de inhumación en ambos casos están insertas o íntimamente ligadas a espacios domésticos de uso cotidiano.

En relación al acompañamiento de las inhumaciones de ca. 3.800-3.500 a.p., las cuatro cuentas de collar líticas decoradas son muy significativas en este contexto. Tanto para el área de estudio como para zonas aledañas, no existen antecedentes previos de este tipo de adorno personal con alta inversión de trabajo artesanal. Sus diseños logrados por medio de finas incisiones con motivos geométricos y antropomorfos remiten estilísticamente a los menhires y máscaras líticas halladas en el valle de Tafí para el $1^{\text {er }}$ milenio de la Era Cristiana (Lazzari et al. 2015). Si bien corresponden a un lapso temporal al menos mil quinientos años posteriores, las diminutas cuentas de TPV1 pudieron haber sido los antecedentes como representaciones de ancestros que luego se materializaron ya como megalitos en el seno de sociedades sedentarias y de base agropastoril. Es interesante destacar que todas las máscaras detectadas fueron depositadas en relación a contextos funerarios (Scattolin et al. 2010) al igual que ocurre en TPV1 con las mencionadas cuentas líticas. Tal como ocurre con los menhires las cuentas también fueron confeccionadas con materia prima local ya que se trata de pequeños guijarros de toba lítica (Osvaldo González comunicación personal 2016), una roca disponible exclusivamente en el río de Los Corrales, lo cual remarca el carácter local de su manufactura por parte de artesanos que habitaron esta zona.

La presencia de semillas de quínoa en las estructuras funerarias de TPV1 (Sector I) es muy relevante por dos motivos: el tipo de contexto -funerario- y la cronología -ca. 3.800-3.500 a.p.-. Por lo tanto el registro de recursos 
vegetales alimenticios en contextos de inhumaciones abre el interrogante sobre su posible función ritual, siendo la quínoa la única planta doméstica asociada y el registro más antiguo vinculado a contextos funerarios del NOA. Además, la situación cronológica previa al establecimiento de los grupos aldeanos agropastoriles, hace de este conjunto de hallazgos un caso único. Con posterioridad (hacia 3.000 a.p.) pero dentro del mismo intervalo transicional se registraron semillas de quínoa en estado seco en $\mathrm{CC} 1$, sitio de uso esporádico para actividades múltiples entre las cuales el procesamiento y consumo de plantas alimenticias tuvo un rol importante. Es decir que en QDLC contamos con semillas de quínoa para el período 4.000-2.000 a.p. procedentes tanto de contextos funerarios como de procesamiento/ consumo. Tal vez pensar en prácticas agrícolas pueda resultar arriesgado pero es indudable la presencia de un vegetal doméstico que remite a manejo humano. Esta hipótesis se ve reforzada por la presencia de numerosos granos de quínoa en contextos domésticos durante el $1^{\text {er }}$ milenio de la Era Cristiana (Oliszewski y Arreguez 2015). Pero con anterioridad, hacia 2.100 a.p. en CC1 junto con la quínoa hay un registro de una mayor diversidad de plantas alimenticias tanto de recolección (algarrobo y chañar) como domésticas (maíz y zapallo). Las semillas de quínoa fueron registradas en todas las capas de CC1 (Arreguez 2016) incluso asociadas al $2^{\circ}$ milenio (650-630 a.p.) mostrando una larga trayectoria de más de 3.000 años en el uso de este recurso en QDLC. En otras regiones de Argentina y Chile también se registraron restos de esta planta doméstica para el intervalo 4.000-2.000 a.p., lo cual permite proponer que en esos momentos ya se la estaba manipulando. Por ejemplo en la Puna meridional argentina, a partir de la recuperación de microrrestos en artefactos de molienda y macrorrestos de tallo, se propone la ocurrencia local de actividades de siembra y cosecha (Aguirre y Rodríguez 2015; Aschero y Hocsman 2011; Babot 2011); en la zona central de Córdoba fueron identificados gránulos de almidón a partir de artefactos de molienda procedentes de una cueva denominada Quebrada del Real I (López et al. 2015); en el norte de Chile en Tulán 54 se identificaron posibles semillas (Mc Rostie 2014) y en la zona central de Chile se registraron en el alero Las Morrenas 1 macrorrestos asociados a grupos cazadores-recolectores cordilleranos (Planella et al. 2014). Durante el período siguiente con la instalación de las sociedades aldeanas agropastoriles la quínoa se convertiría en uno de los cultivos fundamentales en el NOA (Korstanje 2015; Maloberti et al. 2016).

Con respecto a la presencia de artefactos de molienda, cabe mencionar que el uso de esta tecnología para la elaboración de alimentos en las sociedades de cazadores-recolectores precede claramente a los grupos agropastoriles en distintos puntos del NOA (Babot 2011) lo cual puede observarse en TPV1 por la presencia de artefactos de molienda en momentos previos a 3.500 a.p. Estos elementos en conjunto fueron uno de los indicadores de relevancia para definir funcionalmente a TPV1 como una base residencial durante el Holoceno Medio (Martínez et al. 2013). Es decir que esta tecnología habría acompañado a los cazadores-recolectores que habitaron QDLC manteniéndose activa en el lapso transicional. Durante el establecimiento de la aldea en el $1^{\text {er }}$ milenio de la Era Cristiana la tecnología de molienda tuvo un papel primordial. Y siguió siendo importante en el segundo milenio lo cual quedó atestiguado por el registro de artefactos de molienda excavados en la roca de base de CC1. En lo que hace al lapso de interés en este trabajo es probable que los artefactos registrados (un molino y siete manos) hayan sido empleados para la molienda de recursos vegetales de recolección como algarrobo o chañar. En este sentido para este intervalo de transición ha sido registrada una semilla de algarrobo y para el lapso anterior un endocarpo de chañar. Ya en el $1^{\text {er }}$ milenio de la Era Cristiana se registran numerosos endocarpos y semillas de ambas plantas en contextos domésticos. Los análisis de microfósiles en artefactos de molienda develarán cuáles fueron las sustancias procesadas (plantas silvestres y/o domésticas así como otras sustancias orgánicas o inorgánicas). En las zonas ya mencionadas por la presencia de quínoa (centro de Chile y Puna meridional y centro de Córdoba en Argentina) también se registraron artefactos de molienda (Babot 2011; López et al. 2015; Planella et al. 2014). De hecho en los sitios mencionados para Argentina, la presencia de esta planta doméstica fue inferida por el registro de microfósiles en los artefactos. Las semillas de quínoa de TPV1 tienen la particularidad de haber sido recuperadas de contextos inhumatorios por lo cual no es posible asociarlas a prácticas de molienda. Sin embargo, las semillas fechadas en ca. 3.000 a.p. procedentes de contextos de $\mathrm{CC} 1$ sí podrían vincularse con prácticas de molienda.

Respecto a la fauna, tanto para momentos previos como posteriores al lapso bajo análisis, no se observan mayores diferencias en cuanto al número de taxones animales explotados ni en cuanto al porcentaje del NISP por niveles. Aunque sí hay un incremento notable -en los niveles bajo análisis- de restos de Camelidae en relación a momentos previos dentro de este taxón (Izeta et al. 2016). Como no es posible distinguir entre silvestres o domésticos, quedará pendiente de futuros análisis el poder determinar la proporción entre unos y otros con todas las implicancias que tendrían asociadas cada caso.

El análisis cerámico reveló por una parte la existencia de diferencias entre momentos transicionales y aldeanos, por ejemplo en el tratamiento dado a la pieza en el acabado de la superficie ya que el pulido y pintado aparecen exclusivamente en los niveles superiores vinculados al $1^{\text {er }}$ milenio de la Era Cristiana. Por otra parte, no se han observado diferencias marcadas en lo que respecta al tipo de pasta, tipo de cocción y densidad aproximada 
de inclusiones. En lo que hace a las formas presentes, también se evidenció una tendencia temporal hacia una mayor diversidad con la aparición hacia el $1^{\mathrm{er}}$ milenio de la Era Cristiana de piezas pequeñas utilizadas para servir y/o consumir líquidos que posiblemente se relacionan con el consumo de bebidas alcohólicas (como la chicha). Las vasijas grandes asociadas a actividades de cocina se encuentran presentes en ambos momentos reafirmando que este tipo de tecnología ya formaba parte del repertorio tecnológico de los grupos prealdeanos que habitaron QDLC. Debe notarse que para el lapso 3.800-2.500 a.p. hay registros cerámicos que han sido detectados en distintos sitios de la Puna chilena y argentina (Aschero et al. 1999; Fernández 1988-1989; Muscio 2011; Núñez et al. 2006, 2017) así como en las tierras bajas del NOA (Ortiz 2003).

En cuanto a la tecnología lítica de TPV1, es notorio que en conjunto con el cambio en la frecuencia de materias primas en el debitage (cuarzo dominante) hacia ca. 3.500 a.p. ocurre que también hay una mayor frecuencia de artefactos formatizados de cuarzo, tendencia que hacia 1.800 a.p. se acentúa notablemente (Martínez et al. 2013). Una explicación tecnológica de este cambio gradual hacia un mayor uso del cuarzo aún no es clara y requiere de la profundización del análisis y probablemente entren en juego otros factores no específicamente tecnológicos. La identificación de obsidiana de origen puneño en la secuencia de TPV1, abre un interesante espectro social y tecnológico a explorar en cuanto a la definición de un modelo de movilidad e interacción que explique dichas evidencias. No obstante la situación para el momento transicional no reviste particularidades debido a que no hay variaciones sustanciales a lo largo del tiempo en cuanto al uso de las distintas fuentes, manteniéndose constante la conexión entre el área valliserrana y la Puna meridional argentina para el lapso 7.800-1.750 a.p.

La aparición de puntas asignables al sistema arco y flecha hacia este momento transicional de ca. 3.500 a.p. sí marca un importante punto de quiebre ya que el uso del propulsor de gancho deja de ser exclusivo y se complementa con este nuevo sistema de arma. Esta situación no es exclusiva para el NOA, ya que en el norte de Chile ha sido propuesto previamente que el sistema arco-flecha hace su aparición en la Puna de Atacama entre 3.500 y 3.100 a.p. (De Souza 2011). No obstante, tipológicamente el diseño de estas puntas de QDLC asociadas a flechas de arco, tiene una clara conexión técnico-morfológica con puntas de cuarzo de mayor tamaño temporalmente previas. Esta coexistencia en el uso de estos dos sistemas de armas refiere a una amplia gama de técnicas de caza de corta (lanza) y de larga distancia (propulsor) destinadas principalmente a la caza de guanacos silvestres en el área.

Por último se hace notar que, tanto para nuestra área de estudio como a escala regional (NOA), por el momento no existe ningún tipo de antecedentes arquitectónicos correspondientes a ocupaciones arcaicas. Un trabajo reciente revela que, para el área donde se ubica QDLC (norte del Sistema del Aconquija), las primeras unidades habitacionales sensu stricto datan de 1.900 años a.p. Con anterioridad, desde 2.300 a.p. existen evidencias de actividades agropastoriles a través de andenes de cultivo y entierros aislados pero no de espacios domésticos construidos (Oliszewski 2017). La ausencia de evidencias de construcciones previas, permite inferir que las mismas -posiblementefueron elaboradas con materiales perecederos para un uso estacional y/o periódico.

\section{Consideraciones Finales}

A partir de ca. 1.850 a.p. y durante 300 años en QDLC funcionó una aldea agropastoril manifestada por la presencia de casi un centenar de viviendas concentradas y separadas a su vez de extensas áreas con estructuras productivas conformadas por 500 hectáreas de cultivo y 250 corrales. Consideramos que las evidencias presentadas para el lapso 4.000-2.000 a.p. en este trabajo, son indicadores de la existencia de un período de transición local en el que grupos cazadores-recolectores cambiaron gradualmente a un modo de vida aldeano agropastoril.

Hacia 3.800-3.500 a.p. el sitio TPV1 fue una base residencial en la cual se llevaron a cabo múltiples actividades como molienda, manufactura y uso de vasijas cerámicas para cocinar y contener alimentos, elaboración y uso de artefactos líticos confeccionados con materias primas locales, consumo de guanacos producto de la caza con propulsor y arco y flecha (realizada con puntas de proyectil de cuarzo de producción local) e inhumaciones mediante prácticas crematorias con acompañamiento de artefactos como cuentas de collar y semillas de quínoa.

Entre 3.000 y 2.100 a.p. en CC1 (cueva) un contexto de actividades múltiples -pero que no constituyó una base residencial- proporcionó evidencias de la utilización de quínoa al inicio del intervalo sumándose al final del mismo otra planta doméstica (maíz) y plantas silvestres de recolección (algarrobo y chañar).

Por último, hacia el 2.200 a.p. previo a la instalación de la aldea Puesto Viejo, un entierro en cista aislado (EM1) constituye la evidencia más tardía del período transicional 4.000-2.000 a.p.

A excepción del tipo de práctica inhumatoria que varía con el transcurso del tiempo, el resto de las materialidades/prácticas muestran indicios de continuidad hasta momentos en que la aldea se encontraba en pleno funcionamiento.

Respecto a las prácticas de subsistencia, la caza de guanacos a nivel local y la recolección de algarrobo y chañar (llevada a cabo en zonas cercanas de la quebrada de Amaicha a 15-20 km de distancia), 
tendrían una gran antigüedad habiendo comenzado hacia 7.800 a.p. y manteniéndose hasta 1.500 a.p. aun bajo una economía productiva bien establecida. Con respecto a esto último si bien aún no sabemos con certeza cuándo se inició el pastoreo de llamas y la agricultura del maíz y la quínoa, establecidos hacia 1.850 años a.p., sí contamos con indicios de la presencia de quínoa y del recurso Camelidae para el lapso 4.000-2.000 años a.p. que permiten proponer una continuidad en las actividades productivas. Análisis en curso de materiales provenientes de los niveles estratigráficos de TPV1 (osteométricos de la fauna y de microfósiles de los artefactos de molienda) permitirán corroborar la existencia de un proceso de incorporación de actividades productivas que tuvo sus inicios en momentos transicionales.

En lo que hace a otras materialidades es más clara la continuidad entre el intervalo 4.000-2.000 a.p. y el $1^{\text {er }}$ milenio de la Era Cristiana que permiten inferir un proceso transicional local. Así, los artefactos de molienda confeccionados en granitos locales, las puntas de proyectil de cuarzo de diseño local y asociadas a arco y flecha y las vasijas utilizadas en contextos de cocción de alimentos constituyen indicios elocuentes de la existencia de un proceso gradual de cambio que comenzó a gestarse aproximadamente hacia 3.800 años a.p. como un antecedente de la posterior emergencia del sistema aldeano.

Respecto a los eventos de cremación aun cuando no continuaron durante el $1^{\mathrm{er}}$ milenio de la Era Cristiana como práctica, sí dan cuenta de persistencia a través de su construcción en el interior de espacios domésticos y de las cuentas líticas que -a nuestro entender- son micro esculturas que presentan los mismos motivos estilísticos que detentarán luego los menhires y máscaras de las sociedades aldeanas del $1^{\mathrm{er}}$ milenio de la Era cristiana. Todos estos ítems habrían tenido un mismo sentido protector y de identificación que se inició en 3.500 años a.p. continuándose en una tradición que tuvo dos mil años de duración.

Por todo lo expuesto, la información generada a partir de las investigaciones en QDLC es suficiente para definir al período 4.000-2.000 a.p. por una parte, como un intervalo con características propias y diferentes en relación a los estadios previos y posteriores y por otra parte, como el lapso en el cual ya había implícito rasgos de complejidad social que cristalizaron luego en un sólido sistema aldeano que se extendió hasta mediados del $1^{\mathrm{er}}$ milenio de la Era Cristiana.

Las evidencias asignables a este intervalo transicional para otros sitios cercanos, más la abundante información generada desde la Puna argentina y chilena dan cuenta de un período en el cual los grupos humanos estaban explorando y asentándose en diversos espacios simultáneamente, estableciendo relaciones entre ellos que se mantuvieron a lo largo del tiempo. En este sentido el análisis de procedencia de las obsidianas de TPV1 apoya una vinculación con la Puna meridional argentina durante al menos 6.000 años de manera continua. Del mismo modo la cuenta confeccionada sobre valva del Pacífico muestra que las interacciones grupales fueron una constante que caracterizó al período que denominamos transicional.

La continuidad de las investigaciones en QDLC así como en otras zonas de valles y quebradas del NOA permitirá profundizar en la caracterización y comprensión de los procesos prehispánicos ocurridos en el intervalo 4.000 a 2.000 a.p. el cual encierra aún aspectos claves relacionados con el origen de las sociedades aldeanas posteriores.

Agradecimientos: a Marcela Sepúlveda Retamal y Salomón Hocsman coordinadores del Simposio que abordó la rica temática de la "Transición" en el marco del XIX Congreso Nacional de Arqueología Argentina (Tucumán, 2016). A la Comunidad Indígena de Amaicha del Valle y a las entidades que subsidiaron nuestras investigaciones: National Geographic Society (Grants 9581-14 y 9930-16), Agencia Nacional de Promoción Científica y Tecnológica (PICT 2013-1700), Consejo Nacional de Investigaciones Científicas y Tecnológicas (PIP 0141 y PIP 0222) y Secretaría de Ciencia, Arte e Innovación Tecnológica (PIUNT G521). A dos evaluadores anónimos cuyos comentarios y sugerencias permitieron enriquecer el trabajo. A Eugenia Di Lullo un agradecimiento especial.

\section{Referencias Citadas}

Aguirre, G. y F. Rodríguez 2015. Discusiones teóricas y metodológicas en torno a la transición entre la recolección y la agricultura incipiente en Antofagasta de la Sierra, Catamarca. Comechingonia, Revista de Arqueología 19:159-183.

Arreguez, G. 2016. Recursos vegetales alimenticios en un sitio arqueológico de altura: el caso de Cueva de los Corrales 1 (Quebrada de Los Corrales, El Infiernillo, Tucumán). Serie Monográfica y Didáctica 54:952-955.

Aschero, C. y S. Hocsman 2011. Arqueología de las ocupaciones cazadoras-recolectoras de fines del Holoceno Medio de Antofagasta de la Sierra (Puna meridional argentina). Chungara Revista de Antropología Chilena 43 Número Especial 1:393-411.
Aschero, C., R. Zurita, G. Colaneri y A. Toselli 1999. El Bebé de la Peña. Actas del XIII Congreso Nacional de Arqueología Argentina Vol. II, pp. 329-336, Córdoba.

Babot, P. 2011. Cazadores-recolectores de los Andes Centro-Sur y procesamiento vegetal. Una discusión desde la Puna Meridional Argentina (ca. 7000-3200 años A.P.). Chungara Revista de Antropología Chilena 43 Número Especial 1:413-432.

Baied, C. y C. Somonte 2013. Mid-Holocene geochronology, palaeoenvironments, and occupational dynamics at Quebrada de Amaicha, Tucuman, Argentina. Quaternary International 299:8089. 
Bugliani, F., C. Scattolin, A. Izeta, L. Pereyra Domingorena, M. Calo y L. Cortés 2008. Cardonal: un sitio entre los territorios de valles y puna. Cuadernos de la UNJu 32:211-225.

De Souza, P. 2011. Sistemas de proyectiles y cambio social durante el tránsito Arcaico tardío-Formativo temprano de la Puna de Atacama. En Temporalidad, Interacción y Dinamismo Cultural, la Búsqueda del Hombre: Homenaje al Profesor Lautaro Núñez Atencio, editado por A. Hubert, J. González y M. Pereira, pp. 201-246. Universidad Católica del Norte, Ediciones Universitarias, Antofagasta.

Di Lullo, E. 2012. La casa y el campo en la Quebrada de Los Corrales (El Infiernillo, Tucumán): reflexiones sobre la espacialidad en el $1^{\circ}$ milenio D.C. Comechingonia, Revista de Arqueología 16:85-104.

Di Lullo, E., M. Gramajo Bühler y A. Muntaner 2014. Informe técnico inédito: Rescate arqueológico de un entierro (El Molle, Tucumán). Manuscrito en posesión de los autores.

Fernández, J. 1988-1989. Ocupaciones alfareras (2860 \pm 160 años a.p.) en la cueva de San Cristóbal, Puna de Jujuy, Argentina. Relaciones de la Sociedad Argentina de Antropología XVII (2) Nueva Serie:139-178

Gómez Augier, J. y M. Caria 2012. Caracterización arquitectónica y espacial de los complejos habitacionales y productivos del sitio El Divisadero (Cumbres Calchaquíes-Tucumán). Comechingonia, Revista de Arqueología 16:105-127.

Gramajo Bühler, M. 2009. Primera caracterización del conjunto cerámico de La Quebrada de Los Corrales (El Infiernillo, Tucumán). Serie Monográfica y Didáctica 48:121.

Gramajo Bühler, M. 2011. Utilización de Recursos Vegetales en Cueva de Los Corrales 1 (El Infiernillo, Tucumán). Análisis de Macrorrestos Provenientes de Morteros. Tesis de grado. Facultad de Ciencias Naturales e IML, Universidad Nacional de Tucumán, Tucumán.

Izeta, A., J.G. Martínez, O. Brancolini Pedetti y J. Mignino 2016. Zooarqueología de cazadores recolectores y de productores de los valles mesotérmicos del NOA. Primeros resultados para el sitio Taller Puesto Viejo 1. El Infiernillo, Departamento Tafí, Provincia de Tucumán. Ponencia presentada en IV Congreso Nacional de Zooarqueología Argentina, Ushuaia.

Korstanje, A. 2015. Andenes en los Andes: paisajes agrícolas tardíos sin maíz. En Racionalidades Campesinas en los Andes del Sur. Reflexiones en torno al Cultivo de Quinua y otros Vegetales Andinos, editado por P. Cruz, R. Joffre y T. Winkel, pp. 21-58. Institut de Recheche pour le Developpement, Montpellier.

Lazzari, M., J. García Azcárate y C. Scattolin 2015. Imágenes, presencias, memorias. Genealogía y geografía en la piedra durante el primer milenio D.C. En Crónicas Materiales Precolombinas. Arqueología de los Primeros Poblados del Noroeste Argentino, editado por A. Korstanje, M. Lazzari, M. Basile, F. Bugliani, V. Lema, L. Pereyra Domingorena y M. Quesada, pp. 603-633. Sociedad Argentina de Antropología, Buenos Aires.

López, L., M. Medina y D. Rivero 2015. First records of Chenopodium spp./Amaranthus spp. starchs grains and their relevance to the study of the late Holocene human subsistence on Central Argentina. The Holocene 25:288-295.

Maloberti, M., A. Korstanje y M. Quesada 2016. Historizando la producción de quinua en el valle del Bolsón (Departamento Belén, provincia de Catamarca). Mundo de Antes 10:117-141.

Martínez, J.G., M. Caria, A. Grau, A. Izeta, N. Olizsewski, E. Pintar y P. Tchilinguirian 2016. Final Report National Geographic Society's Committee for Research and Exploration Grant Number: 9581-14. Project "The earliest hunter-gatherers groups in the valleys of NW Argentina: a history of more than 7000 years". Manuscrito en posesión de los autores.
Martínez, J.G., E. Mauri, C. Mercuri, M. Caria y N. Oliszewski 2013. Mid-Holocene human occupations in Tucumán (Northwest of Argentina). Quaternary International 307:86-95.

Martínez, J.G., N. Oliszewski, C. Aranda, L. Luna, E. Naharro y M. Pérez 2017. Prácticas en torno a la muerte en la Quebrada de Los Corrales, El Infiernillo, Tucumán (3800-1500 años AP). Ponencia presentada en XIII Jornadas Nacionales de Antropología Biológica, Necochea, Buenos Aires.

McRostie, V. 2014. Arboricultura y silvopastoralismo en el período Formativo (1.400 a.C.-500 d.C.) de la cuenca del Salar de Atacama. Chungara Revista de Antropología Chilena 46:543557.

Mercuri, C., M. Gramajo Bühler, E. Mauri y M. Pantorrilla Rivas 2016. Evaluando coherencia e integridad del registro arqueológico de TPV1 (El Infiernillo, Tucumán, Argentina). Primer acercamiento desde la evidencia cerámica. Mundo de Antes 10:173-184.

Muscio, H. 2011. Ocupaciones humanas a cielo abierto de finales del Holoceno Medio y comienzo del Holoceno Tardío en el Valle de San Antonio de los Cobres, puna de Salta. Comechingonia, Revista de Arqueología 15:171-190.

Núñez, L., I. Cartajena, C. Carrasco, P. de Souza y M. Grosjean 2006. Emergencia de comunidades pastoralistas formativas en el sureste de la Puna de Atacama. Estudios Atacameños 32:93-117.

Núñez L., I. Cartajena, C. Carrasco, P. López, P. de Souza, F. Rivera y B. Santander 2017. Presencia de un centro ceremonial formativo en la circumpuna de Atacama. Chungara Revista de Antropología Chilena 49:3-33.

Oliszewski, N. 2017. Las aldeas "Patrón Tafí” del sur de Cumbres Calchaquíes y norte del Sistema del Aconquija. Comechingonia, Revista de Arqueología XXI (2), en prensa.

Oliszewski, N. y G. Arreguez 2015. Los recursos vegetales alimenticios de la Quebrada de Los Corrales en El Infiernillo, Tucumán, durante el $1^{\circ}$ milenio d.C. Comechingonia, Revista de Arqueología 19(2):111-140.

Oliszewski, N., M. Gramajo Bühler, E. Mauri, G. Míguez, A. Muntaner y M. Pantorilla Rivas 2010. Caracterización de un enterratorio humano en la Quebrada de Los Corrales (El Infiernillo, Tucumán). Intersecciones en Antropología 11:315319.

Oliszewski, N., J.G. Martínez y M. Caria 2008. Ocupaciones prehispánicas de altura: el caso de Cueva de los Corrales 1 (El Infiernillo, Tafí del Valle, Tucumán). Relaciones de la Sociedad Argentina de Antropología XXXIII:209-221.

Oliszewski, N., J.G. Martínez, E. Di Lullo, M. Gramajo Bühler, G. Arreguez, H. Cruz, E. Mauri, C. Mercuri, A. Muntaner y G. Srur 2015. Contribuciones al estudio de sociedades aldeanas en el Noroeste Argentino: el caso de la quebrada de Los Corrales (El Infiernillo, Tucumán). En Crónicas Materiales Precolombinas. Arqueología de los Primeros Poblados del Noroeste Argentino, editado por A. Korstanje, M. Lazzari, M. Basile, F. Bugliani, V. Lema, L. Pereyra Domingorena y M. Quesada, pp. 51-79. Sociedad Argentina de Antropología, Buenos Aires.

Ortiz, G. 2003. Estado actual del conocimiento del denominado Complejo o tradición Cultural San Francisco, a 100 años de su descubrimiento. En La Mitad Verde del Mundo Andino, Investigaciones Arqueológicas en la Vertiente Oriental de los Andes y las Tierras Bajas de Bolivia y Argentina, editado por G. Ortiz y B. Ventura, pp. 23-71. EdiUNJu, Editorial de la Universidad Nacional de Jujuy, Jujuy.

Palamarczuk, V., R. Spano, F. Weber, D. Magnífico, S. López y M. Maniasiewicz 2007. Soria 2. Apuntes sobre un sitio temprano en el Valle de Yocavil, Catamarca, Argentina. Intersecciones en Antropología 8:121-134. 
Planella, T., L. López y C. Bruno 2014. La domesticación y distribución prehistórica. En Estado del Arte de la Quinua en el Mundo 2013, editado por D. Bazile, D. Bertero y C. Nieto, pp. 33-48. FAO, Santiago de Chile y CIRAD, Montpellier.

Scattolin, C., F. Bugliani, L. Cortés, L. Pereyra Domingorena y C. Calo 2010. Una máscara de cobre de tres mil años. Estudios arqueometalúrgicos y comparaciones regionales. Boletín del Museo Chileno de Arte Preolombino 15:25-46.

Scattolin, C., F. Bugliani, L. Pereyra Domingorena, L. Cortés, M. Lazzari, A. Izeta y C. Calo 2015. Habitar, circular, hacer. El punto de vista de la quebrada. En Crónicas Materiales Precolombinas. Arqueología de los Primeros Poblados del Noroeste Argentino, editado por A. Korstanje, M. Lazzari M. Basile, F. Bugliani, V. Lema, L. Pereyra Domingorena y M.
Quesada, pp. 427-464. Sociedad Argentina de Antropología, Buenos Aires.

Spano, R. y A. Álvarez Larrain 2015. Entre muros y vasijas: entierros y memoria en Soria 2, Valle de Yocavil. En Crónicas Materiales Precolombinas. Arqueología de los Primeros Poblados del Noroeste Argentino, editado por A. Korstanje, M. Lazzari M. Basile, F. Bugliani, V. Lema, L. Pereyra Domingorena y M. Quesada, pp. 485-587. Sociedad Argentina de Antropología, Buenos Aires.

Srur, G. 2009. Estudio zooarqueológico en el sitio Cueva de los Corrales 1 (quebrada de Los Corrales, Tafí del valle, provincia de Tucumán). Ponencia presentada en VIII Jornadas de Jóvenes Investigadores en Ciencias Antropológicas del Instituto Nacional de Antropología y Pensamiento Latinoamericano, Buenos Aires. 